\title{
LOS MOVIMIENTOS SOCIALES Y LA BATALLA POR EL SIGNIFICADO DE LA CRISIS DEL CORONAVIRUS.
}

\section{SOCIAL MOVEMENTS AND THE BATTLE FOR THE MEANING OF THE CRISIS OF THE CORONAVIRUS}

Fecha recepción: 10 de junio de 2020 / fecha aceptación: 22 de junio de 2020

Cómo citar este artículo:

Pleyers, G.(2020). Losmovimientossocialesylabatallaporelsignificadodelacrisis del coronavirus. Revista Pensamiento y Acción Interdisciplinaria, 6(1), 108-121.

DOI: http://doi.org/10.29035/pai.6.1.108

\section{Resumen}

Este artículo se centra en la lucha sobre los significados de la crisis planteada por la pandemia COVID-19. Interpretar las crisis es una función clave de los movimientos sociales que puede tener un impacto importante en la transformación social. Los intelectuales progresistas y los movimientos para la justicia social la consideran como una crisis multidimensional que abrió oportunidades para construir un mundo más justo. Sin embargo, las secuelas de la crisis financiera mundial de 2007-2008 sugieren un enfoque más cauteloso al examinar la conexión entre las crisis y el cambio social. Si bien los movimientos populares y los intelectuales progresistas pueden influir en el significado de la crisis y en su resultado, compiten en este campo con actores reaccionarios, capitalistas y estatales que también tratan de imponer un significado de la crisis y una orientación al mundo que saldrá ella.

Palabras clave: Covid-19, movimientos sociales, contra-movimientos, producción de sentido, horizontes de futuro, escala global

\footnotetext{
1 Profesor investigador del FNRS en la Universidad Católica de Lovaina, Bélgica. Vicepresidente de la Asociación Internacional de Sociología (ISA) 2018-2022. Presidente del Research Committee 47 "Social classes and social movements" en ISA, 2014-2018. Promotor de la iniciativa Social Movements and the Global Age (SMAG). Autor de numerosas publicaciones en todo el mundo. Su último libro publicado en español es "Movimientos sociales en el siglo XXI" (Clacso, 2018). Correo electrónico: geoffrey.pleyers@uclouvain.be. Este texto ha contado con la revisión y edición de Juan Pablo Paredes, académico en la Facultad de Ciencias Sociales y Económicas de la Universidad Católica del Maule.
} 


\begin{abstract}
This article focuses on the struggle over the meanings of the crisis raised by the COVID-19 pandemic. It highlights the role of interpreting the crisis as a key function of social movements that may have a major impact in social transformation. Progressive intellectuals and social justice movements consider the COVID-19 crisis as a multi-dimensional crisis that has opened opportunities to build a fairer world. The aftermath of the 2007-2008 global financial crisis suggests a more cautious approach when examining the connection between crisis and social change. While popular movements and progressive intellectuals may have an impact on the meaning of the crisis and on its outcome, they compete with reactionary, capitalist and state actors that also seek to shape the meaning of the crisis and the world that may come out of it.
\end{abstract}

Keywords: Covid-19, social movements, counter-movements, production of meaning, future horizons, global scale

\title{
Introducción
}

Numerosos intelectuales progresistas, movimientos populares y activistas por la justicia social comparten una convicción: la pandemia ha puesto de manifiesto los límites del sistema capitalista dominado por las empresas transnacionales junto con el daño que gobiernos han causado en el último decenio, particularmente por las políticas de austeridad. Afirman la necesidad de un modelo societal que dé mayor importancia a los seres humanos, produzca menos desigualdad y cuente con mejores sistemas de salud pública.

En un artículo reciente, apunté una serie de roles que cumplieron los movi109 mientos sociales durante la pandemia y el confinamiento (Pleyers, 2020). Crearon redes de solidaridad y de apoyo mutuo, vigilaron las políticas de los gobiernos para afrontar la crisis y llevaron a cabo programas de educación popular y de información sobre el virus, difundiendo las maneras de protegerse y cuidarse contra la pandemia en los barrios populares. El presente artículo, dividido en cinco secciones, se enfoca en uno de estas funciones de los movimientos sociales durante las situaciones de crisis: interpretar los sucesos para abrir horizontes sociales alternativos.

La evaluación de los impactos de los movimientos sociales, es un debate permanente en el campo de estudio de estos actores colectivos. La mayoría de la literatura se enfoca en las orientaciones estratégicas y en los impactos en la política institucional. Otros autores que apuntan regularmente a enfoques "cognitivos" o "culturales" de los movimientos sociales, consideran la producción de significados (Eyerman y Jamison, 1991), de conocimiento (Sousa Santos, 2019) o de narrativas (Polletta, 1998) como una de sus principales contribuciones. Siguiendo ese mismo camino, este artículo subraya la importancia del trabajo de interpretación de la crisis multidimensional que surgió a raíz de la pandemia de la COVID-19, realizada 
por los movimientos sociales, junto con activistas e intelectuales comprometidos en todos los continentes, como también investigadores en ciencias sociales que publicaron miles de artículos de opinión durante el confinamiento. Afirmaron que la crisis debe ser tratada como un momento de ruptura que traerá cambios significativos en nuestras vidas, nuestras sociedades y nuestro mundo.

Sin embargo, como señalo en la segunda sección, una comparación con los cambios en las políticas sociales y económicas después de la crisis financiera de 2007-2008, invita a ser más prudentes al evaluar los impactos de las crisis en el cambio social. En particular, llama a no confundir los deseos (legítimos) de una sociedad más justa con necesidades históricas. La urgente necesidad de un mundo más justo, social y ecológicamente, no es un argumento suficiente para que esto ocurra.

Esto no debe llevar a minorar la importancia de las acciones de los actores populares y progresistas, en abrir nuevos horizontes para futuros alternativos. Pero, como argumenta la tercera parte del artículo, invita a adoptar un análisis relacional, tomando en cuenta no solo el trabajo interpretativo de los actores progresistas y populares, sino también la agencia de los actores que defienden el capitalismo global así como los movimientos reaccionarios (Pleyers, 2018, cap. 5). Diferentes actores, progresistas, capitalistas y reaccionarios, compiten para imponer diferentes narrativas de la crisis y del mundo que debe emerger de ella. Además, como sostiene Jasper (2012), también se debe incorporar a los gobiernos como actores relevantes en la arena de definición por los significados de la crisis.

Frente a una crisis global sin precedente en la historia moderna, la batalla por el significado y el impacto de esta crisis se juega a escala global. Sin embargo, la cuarta sección del artículo argumenta que no se trata de un campo de batalla único y homogéneo. Si bien se articulan las diversas escalas, desde lo local a lo global, se mantiene diferencias importantes entre ellas, al considerar que se lleva a cabo en espacios públicos fragmentados. Cierra el escrito con una breve conclusión sobre los puntos anteriores, en relación al futuro.

\section{Interpretar la crisis}

Abrir nuevos horizontes de lo posible siempre ha sido una tarea destacada de los movimientos sociales. Cuando los actores dominantes imponen la idea de que "no hay alternativa" al orden mundial, los movimientos sociales los desafían afirmando que "otro mundo es posible", como decía el eslogan del Foro Social Mundial. Ellos introducen debates y reflexiones en un orden que se da por sentado, lo que contribuye a la capacidad de una sociedad de transformarse, "de producirse a sí misma" más conscientemente, como nos dijo el sociólogo Alain Touraine (1973). 
Este papel es aún más importante en tiempos de crisis. Las crisis rompen las rutinas y el "business as usual". Ofrecen oportunidades para reflexionar individual y colectivamente sobre nuestros valores comunes y objetivos colectivos. En la crisis inédita y multidimensional del coronavirus, también "todo lo que era solido se desvanece en el aire" (Sousa Santos, 2020). La pandemia COVID-19 ha sacudido profundamente nuestra vida cotidiana y muchas de las "certezas" de nuestro sistema económico, político y social. Cosas impensables hace tres meses se han convertido en la realidad cotidiana actual, tanto en la vida personal como en la sociedad. La pandemia ha sacudido los dogmas económicos que han regido el mundo durante décadas (Teivainen y Huotari, 2020). Obligados a implementar un confinamiento para limitar la propagación del virus, los gobiernos enmarcan un "retorno a la normalidad" como el propósito de una "unidad nacional2" que reúna a los políticos, las empresas, los trabajadores y toda la población en una lucha común contra el COVID-19. Los activistas insisten, por su lado, en que lo que se presenta como "la normalidad", es en realidad parte constitutiva del problema y no es un buen camino para enfrentarlo. "Nada podría ser peor que una vuelta a la normalidad" afirma la activista india Arundhati Roy 3 .

Las principales preocupaciones y exigencias que han movilizado a los activistas y ciudadanos progresistas en los últimos años, han adquirido aún mayor importancia, visibilidad y urgencia durante la crisis: menos corrupción y menos poder de la élite, más democracia, participación, justicia social y dignidad.

Junto a cientistas sociales comprometidos, expertos y activistas de movimientos populares mostraron que la propagación del virus y las altas tasas de mortalidad están profundamente relacionada con las desigualdades sociales. Por ejemplo, la Asociación para el Desarrollo de Barrios y Viviendas de la Ciudad de Nueva York, ha revelado cuán estrechamente la incidencia de COVID-19 sigue la geografía de los barrios con mayorías de personas de color y con inquilinos que pagan más del 30\% de sus ingresos por su vivienda (Afridi \& Walters, 2020), dejando ver el impacto dramático de las desigualdades en esta crisis y en la tasa de mortalidad de la pandemia.

Las políticas de salud pública y las desigualdades sociales importan tanto como la forma en que nuestros cuerpos reaccionan, cuando se trata de las consecuencias mortales del virus. La pandemia y el confinamiento constituyen tanto una experiencia compartida por miles de millones de personas en todo el mundo como un desafío muy diferente que se enfrenta en condiciones profundamente desiguales en cuanto al trabajo, la vivienda y el acceso a la salud (Purkayastha, 2020).

2 El primer discurso de Macron sobre la pandemia se tituló "La Francia Unida es nuestro mejor activo en el período problemático que estamos atravesando con el Covid-19. Aguantaremos nosotros juntos." https://www.elysee.fr/emmanuelmacron/2020/03/12/adresse-aux-francais

3 Arundhati Roy (2020/04/17): "The Pandemic Is a Portal", Yes Magazine. www.yesmagazine.org/video/coronavirus-pandemic-arundhati-roy/ 
Basándose en estos análisis, investigadores, intelectuales progresistas y actores populares atribuyen un fuerte significado social y político a la crisis, dejando ver que no se trata solo de una crisis sanitaria. Por lo tanto, intelectuales progresistas y actores de movimientos populares dibujaron innumerables escenarios para "futuros alternativos". La mayoría ve en la crisis de la pandemia la confirmación y profundización de la crisis que han denunciado en trabajos anteriores, enmarcándola como la crisis de la globalización corporativa del capitalismo (Amadeo, 2020), del antropoceno (Kothari et al., 2020) o una crisis de la civilización (Escobar, 2020; 2018). Han circulado decenas de artículos de opinión y peticiones que afirman que es necesario construir una sociedad más justa después de la pandemia, con servicios públicos más sólidos y acceso a la atención sanitaria para todos, ingresos universales y mejores condiciones de trabajo.

\section{De la crisis al cambio social}

\section{¿Primeros impactos prometedores?}

En el calor de la pandemia, los movimientos progresistas han tenido cierto éxito en la difusión de algunos argumentos mucho más allá de los círculos de activistas, al menos en las democracias de Europa Occidental. Tras años de austeridad en los servicios públicos, los gobiernos subieron los presupuestos para mitigar los efectos de la pandemia y limitar la crisis económica y social. El Estado interviene masivamente en la economía, y varios gobiernos abogan por una relocalización de la producción de "bienes esenciales". En Europa occidental, los campeones de los recortes presupuestarios en los hospitales públicos, ahora participan en las sesiones cotidianas de aplausos de apoyo al personal médico y sanitario que cumplen labores de salud durante la pandemia. Desde Ángela Merkel, pasando por Emmanuel Macron hasta Boris Johnson, declararon que consideraban que el Estado de bienestar y los hospitales públicos eran características cruciales de la identidad nacional de su país.

Hasta febrero 2020, el gobierno francés implementó planes de austeridad a los hospitales públicos y se negó a atender las reivindicaciones de las enfermeras y los médicos que llevaron a cabo la huelga más larga del sector en Francia. Su ambicioso "plan de reformas" tenía como objetivo disminuir la intervención del Estado en la economía y ahorrar dinero en los sectores de servicios públicos, entre ellos el sector sanitario.

En sus dos discursos a la nación desde el inicio del confinamiento, en marzo 2020, la perspectiva de Emmanuel Macron fue muy distinta. Calificó a los trabajadores de los hospitales públicos como héroes. El Estado aumentó el presupuesto de los hospitales públicos durante la crisis, y el Presidente juró que habría 
cambios importantes en las políticas públicas", explicando que "el día después de la pandemia no será como el día antes" ${ }^{5}$, incluso asumiendo la necesidad de cambios a futuro: "Tendremos que cuestionar el modelo de desarrollo en el que nuestro mundo ha estado comprometido durante las últimas décadas"."

Ferviente defensor del libre comercio antes de la pandemia, el Presidente francés habla ahora de "soberanía económica", concede préstamos masivos a las "empresas nacionales", y muestra mayor aprecio por lo público. La pandemia ha logrado aquello que no pudo alcanzar una de las huelgas generales más largas de la historia francesa, entre noviembre 2019 y marzo 2020, para oponerse y parar la reforma de las pensiones promovido por el programa neoliberal del Presidente Macron.

\section{Lecciones de la crisis financiera mundial}

Este cambio de postura y de discursos resuena con declaraciones de otro presidente neoliberal francés, hace 12 años, durante la crisis financiera mundial. El 23 de octubre de 2008, Nicolás Sarkozy declaró "la ideología de la dictadura del mercado y la impotencia pública ha muerto con la crisis financiera" 7 ". Los altermundialistas no podrían haberlo dicho mejor. Durante el Foro Social Europeo de 2008, celebraron el hecho que "la crisis [financiera] nos ha dado la razón. Ahora los gobiernos tendrán que tener en cuenta nuestras propuestas y detener sus políticas neoliberales".

Lamentablemente no fue así y sabemos lo que pasó a continuación. En los años que siguieron a la crisis financiera, la narrativa dominante puso el peso de la crisis económica en los Estados de bienestar europeos, abriendo paso a políticas de austeridad, que profundizaron la crisis social y las desigualdades, y facilitando el éxito de la derecha populista y xenófoba.

Lo sucedido en los años posteriores a la crisis financiera mundial del 2008, en la política europea, dejan tres lecciones en lo que respecta al cambio social. La primera es que, independientemente de su magnitud, una crisis por sí misma no generará el cambio social. Este depende mucho más de la capacidad de los actores sociales para poner de relieve las cuestiones que genera la situación histórica, promoviendo visiones políticas y una racionalidad económica alternativa (Pleyers, 2010, capítulo 10). Los actores sociales desempeñan un papel importante en la sensibilización de la opinión pública, en la formulación de propuestas inéditas y

4 Mauduit L. (2020/04/12) Retraites, hôpital: la troublante conversion d’Emmanuel Macron, Mediapart, https://www.mediapart.fr/journal/france/120420/retraites-hopital-la-troublante-conversion-d-emmanuel-macron

5 https://www.elysee.fr/emmanuel-macron/2020/03/16/adresse-aux-francais-covid19

6 Présidence de la République, (2020, March 12) "Adresse aux Français". Retrieved 28 May 2020, from https://www.elysee.fr/emmanuel-macron/2020/03/12/adresse-aux-francais

7 Discurso del presidente Sarkozy sobre "las medidas tomadas para apoyar la economía", 23 de octubre 2008. 
en la implementación de alternativas concretas. No existe una forma predeterminada de salir de ninguna crisis, menos de la pandemia. Por lo mismo, la actuación de los agentes sociales durante la crisis y sus secuelas tendrá repercusiones en la sociedad, la economía y la política. Y esto no debe desatenderse.

Una segunda lección es que los buenos argumentos y los hechos no son suficientes para configurar la racionalidad económica y las políticas del mundo que saldrá de la crisis. El sociólogo Raymond Boudon (1989: capítulo 9), ha demostrado que la "verdad" en las teorías económicas tiene más que ver con su capacidad de forjar un consenso provisional que con su validez científica, que siempre es muy discutible. Asimismo, la pandemia del coronavirus es al mismo tiempo una serie de hechos que nadie puede negar y una realidad social que es reinterpretada de manera muy diferente por distintos actores sociales. Cada corriente va interpretando la crisis a la luz de su narrativa anterior, de manera que refuerza sus convicciones previas y su visión del mundo. Los hechos y las ciencias ya no son referencias compartidas, sino que están sujetos a reinterpretaciones por parte de ideologías y líderes populistas que desconfían de ella. La fe de J. Habermas (1998), en un espacio público deliberativo y en una democracia argumentativa se desvanece en el mundo de las redes sociales, de los espacios públicos fragmentados, de las fake news y de los líderes populistas.

Como consecuencia, y esta es la tercera lección, la batalla sobre el significado de la crisis es una instancia crucial. Los actores que contribuirán a dar forma a la narrativa dominante de la crisis, allanarán el camino del mundo que nacerá de la pandemia. Es sobre la base de esta narrativa que se impulsarán las nuevas políticas en materia de salud pública, pero también en materias económicas, sociales, culturales y democráticas. Como dijo el destacado académico y activista latinoamericano Arturo Escobar, "es crucial en esta etapa contar con narraciones sobre otras formas de vida y tenerlas listas ${ }^{8 \prime}$.

Cada sector de los movimientos populares y progresistas promueve una perspectiva que inserta la pandemia en una meta-narrativa en torno a sus demandas histórica y la visión del mundo que viene desarrollando, que actúa como el "marco maestro" (Snow \& Benford, 2002) en su trabajo de producción del significado de la crisis.

Algunos muestran la experiencia de la pandemia desde el punto de vista de las desigualdades urbanas, otros desde una perspectiva interseccional, insistiendo en el peso de las tareas del cuidado que soportan las mujeres, y en particular las mujeres de color ${ }^{9}$, tanto en las familias, como en las comunidades y en los hospitales públicos. Los intelectuales progresistas vinculan la pandemia con los estragos del capitalismo ("El capitalismo es el verdadero virus" se ha convertido en

8 "Coronavirus y disputas por lo público y lo común en América Latina", Seminario en línea organizado por CLACSO, ALAS e ISA, 9 de abril 2020. https://youtu.be/pOFQlsesLf8

9 Hirsch, A. (2020, May 7). After coronavirus, black and brown people must be at the heart of Britain's story | Afua www. theguardian.com/commentisfree/2020/may/07/coronavirus-black-brown-people-britain-ethnic-minorities 
un eslogan en las redes sociales) y la crisis ecológica. Los movimientos populares latinoamericanos enmarcan la crisis en la meta-narrativa que se construyó en la confluencia de los movimientos indígenas, feministas, ecológicos y de justicia social durante la última década: "la crisis revela las profundas crisis sociales, políticas y ecológicas a las que nos enfrentamos. Detrás de la crisis sanitaria, hay una crisis de civilización ${ }^{10 \prime \prime}$.

\section{Contra-movimientos}

Sin embargo, los movimientos progresistas no están solos en esta batalla para imponer el significado de la crisis de la COVID-19. Se enfrentan a dos tipos de "contra-movimientos" (Polanyi, 1944): las élites capitalistas globales, que Leslie Sklair (2001) propone analizar como un "movimiento social para el capitalismo global", y los movimientos reaccionarios.

\section{Defender el capitalismo global}

Los años que siguieron a la crisis financiera del 2008, demostraron la capacidad de los defensores del capitalismo global para imponer su narrativa y el significado de la crisis. En unos pocos años, consiguieron que el significado de la crisis y el enfoque de las políticas pasaran del colapso del capitalismo financiero, a las deudas de los Estados de bienestar, abriendo así camino para un decenio de políticas de austeridad. Una década más tarde, los actores que parecen estar más capacitados para aprovechar las oportunidades abiertas por la crisis y la ruptura de los dogmas económicos pueden estar del mismo lado. En muchos países, no solo europeos, los paquetes de estímulo han canalizado cantidades considerables de dinero público a grandes empresas. En los Estados Unidos, el primer plan de coronavirus les dio 500.000 millones de dólares, cinco veces más que lo entregado a los hospitales públicos.

Mientras los activistas afirmaban que la crisis debería ser una oportunidad para impulsar un modelo económico más ecológico, las compañías petroleras recibieron su parte de dinero público y los gobiernos establecieron rescates masivos y préstamos para las aerolíneas ${ }^{11}$. En una lógica capitalista mundial, los países y las empresas ven la crisis también como una oportunidad para ganar nuevos mercados y los que estén dispuestos a competir en ellos, tendrán ventajas significativas.

10 Montserat Sagot, Online seminar "Coronavirus y disputas por lo público y lo común en América Latina", CLACSO, ALAS and ISA, April 2020. https://youtu.be/pOFQlsesLf8

11 https://stay-grounded.org/savepeoplenotplanes 
Además, Klein (2009) ha demostrado cómo las élites capitalistas lograron aprovechar las crisis como una oportunidad para imponer y reforzar políticas neoliberales. Este escenario podría repetirse con la crisis de la COVID-19, como lo sugiere por ejemplo las primeras medidas tomadas por el gobierno ecuatoriano para reforzar políticas neoliberales durante el confinamiento. En otros países, si bien los Estados subieron sus gastos en la salud pública durante la pandemia, no se puede excluir que la crisis económica y el aumento de la deuda pública a raíz de la crisis socio-sanitaria, podrían usarse como argumento para implementar reducciones en las políticas sociales.

\section{Movimientos reaccionarios}

Los movimientos reaccionarios también han sido muy activos durante el bloqueo comercial debido al confinamiento de la población. Diversas teorías conspirativas se extendieron por las redes socio-digitales, dando lugar a una "infodemia" sin precedentes (Zarocostas, 2020). Sus discursos integraron la crisis en una narrativa más amplia de "guerra de culturas" que culpa de la pandemia a los migrantes, a la "sociedad multicultural" y al "marxismo cultural"12.

Los activistas de extrema derecha protestaron contra el cierre y las cuarentenas incluso cuando la pandemia estaba en su apogeo. En los Estados Unidos ${ }^{13}$, miles marcharon en contra del confinamiento, del cierre de negocios y del comercio. Las protestas iniciaron en Michigan el 15 de abril y tuvieron lugar casi todas las capitales de Estado, con el apoyo de Donald Trump. En Brasil, el propio presidente participa en las protestas contra las medidas sanitarias impuestas por los gobernadores de diversos Estados ${ }^{14}$. En Alemania, las protestas en contra del confinamiento juntaron activistas anti-vacunas, antisemitas, ultraliberales y ciudadanos que difundieron teorías conspiracionistas que enmarcan el cierre como el primer paso de un golpe de estado impuesto por Ángela Merkel ${ }^{15}$. Mientras tanto, sacerdotes de iglesias conservadoras neo-pentecostales afirmaron "la fe, y no la ciencia, nos salvará16", y apoyaron a líderes populistas que abogaron por reabrir los templos durante el cierre.

12 Es por ejemplo el argumento de este texto y de la video que circulo entre las redes socio-digitales xenófobos "Bélgica, el siniestro país de modelo marxista cultural que lidera muertes por millón de habitantes" www.antronio.cl/threads/elsiniestro-pa\%C3\%ADs-de-modelo-marxista-cultural-que-lidera-muertes-por-mill\%C3\%B3n-de-habitantes.1322094/

13 Vogel, K. P., Rutenberg, J., \& Lerer, L. (2020, April 21). The Quiet Hand of Conservative Groups in the Anti-Lockdown Protests. The New York Times. https://www.nytimes.com/2020/04/21/us/politics/coronavirus-protests-trump.html

14 Travis Waldron (2020, May 20) "Brazil is the new epicentre of the Global Coronavirus pandemic", Huffington Post.

15 Baumgärtner M. et al. (2020, May 14). The Corona Conspiracy Theorists, Der Spiegel International. Retrieved 27 May 2020, from https://www.spiegel.de/international/germany/the-corona-conspiracy-theorists-protests-in-germany-see-fringe-mix-with-the-mainstream-a-8a9d5822-8944-407a-980a-d58e9d6b4aec

16 Michelle B. (2020, April 3). Can faith healing work by phone? Charismatic Christians try prayer to combat the coronavirus. Washington Post. Retrieved 25 May 2020, from https://www.washingtonpost.com/religion/2020/04/03/supernaturalhealing-christian-faith-coronavirus-pandemic 
La pandemia generó un crecimiento del racismo en todas las regiones del mundo, contra los trabajadores migrantes en la India o en China, contra los asiático-americanos en los Estados Unidos, contra las minorías y los pobres acusados de propagar la pandemia, y en todo el mundo, contra los refugiados. El Secretario General de las Naciones Unidas alertó sobre un "tsunami de odio y xenofobia, chivos expiatorios y alarmismo", desatado por la pandemia. En sus palabras:

\begin{abstract}
"A medida que las especulaciones giraban en torno al lugar de origen del virus, se ha vilipendiado a los migrantes y refugiados como fuente del virus y se le ha negado el acceso al tratamiento médico. Mientras, los periodistas, los que denunciaban irregularidades, los profesionales de la salud, los trabajadores humanitarios y los defensores de los derechos humanos están siendo atacados simplemente por hacer su trabajo ${ }^{17 \prime \prime}$.
\end{abstract}

\title{
Los gobiernos en la batalla
}

Los movimientos sociales no son los únicos actores que buscan forjar el significado de la crisis actual. Los Estados-naciones se presentaron como los mayores protagonistas frente a la pandemia. Los gobiernos invierten significativamente en la batalla sobre el significado de la crisis para defender su gestión, definir la situación e imponer su narrativa. El Partido Comunista de China vigila cuidadosamente su imagen de gobierno eficiente para controlar la pandemia, y encarcela a quienes se atrevan a desafiar su narrativa o a criticar la gestión de la crisis por parte de Xi Jinping ${ }^{18}$. En Hungría, debido a las "medidas de emergencia” contra el coronavirus, la libertad de expresión se ha restringido aún más ${ }^{19}$. En Brasilia y en Washington, los líderes populistas defienden una visión del mundo que parece capaz de reinterpretar cualquier hecho de la pandemia, incluso después de no haber actuado para frenarla.

Este juego de poder para dar forma a la narración no es exclusivo de los estados autoritarios y de los líderes populistas. El gobierno francés está particularmente atento a los discursos públicos sobre su gestión de la crisis. En varias ocasiones, la policía ha intervenido para intimidar ciudadanos que colgaron banderolas criticando la gestión de la crisis por parte del presidente ${ }^{20}$. El pasado 26 de abril, una mujer pasó cuatro horas bajo custodia policial por haber colgado

17 UN Secretary-General Denounces 'Tsunami' of Xenophobia Unleashed amid COVID-19, NYC: UN. https://www.un.org/press/en/2020/sgsm20076.doc.htm

18 Davidson H. (2020/04/08) Critic who called Xi a 'clown' over Covid-19 crisis investigated for 'serious violations', The Guardian. https://www.theguardian.com/world/2020/apr/08/critic-xi-jinping-clown-ren-zhiqiang-covid-19-outbreak-investigated-china

19 Hungarian Helsinki Committee (2020) Emergency Law Gives Carte Blanche Powers to Government: Free Media and Human Rights Defenders Needed More Than Ever. (2020, March 31). www.helsinki.hu/en/emergency-law-gives-carteblanche-powers-to-government

20 Polloni C. (2020/04/16) Pour des banderoles au balcon, la police à domicile. www.mediapart.fr/journal/france/160420/ pour-des-banderoles-au-balcon-la-police-domicile 
una pancarta que decía: “Macronavirus, ¿cuándo se detendrá?”, exponiendo la responsabilidad del mandatario en la difusión de la crisis. Muchos gobiernos buscaron ocultar sus errores y fallas en la gestión de la pandemia durante su fase inicial, culpando de la difusión del virus a los ciudadanos que no cumplen con las reglas de confinamiento. En términos de biopolítica y de control social, regímenes democráticos adoptaron, en ocasiones, medidas que cuestionan el Estado de derecho. Las políticas adoptadas durante la pandemia podrían allanar el camino hacia una nueva era más autoritaria, con una biopolítica basada en las nuevas tecnologías y la inteligencia artificial y el incremento del control de los ciudadanos por la policía.

\section{Un campo de batalla fragmentado}

La batalla sobre el significado social y societal de la pandemia tiene al mundo como escenario. Sin embargo, su dificultad radica en ser un debate muy segmentado. Se pueden reconocer, al menos, tres niveles o espacios.

Primero, tiene lugar en un espacio mediático complejo y altamente fragmentado. Las redes socio-digitales abren espacios de expresión y la difusión de opiniones, información divergente e interpretaciones variadas de la crisis. Sin embargo, fragmentan el espacio público. Cada orientación política inunda a sus seguidores con noticias y análisis que fortalecen su propia visión del mundo. Los medios de masas, y en particular los canales de televisión y los periódicos (ahora por sus sitios internet) siguen siendo los principales protagonistas de la "fabrica del consenso" y de la elaboración de opiniones. En la mayoría de los países, la pandemia ha matizado los conflictos políticos, uniendo una gran parte de la población contra una amenaza común. En contraste, tanto en Brasil como en Estados Unidos, la pandemia fortaleció la polarización de la sociedad, ya que cada polo la interpretó en el marco de su propia visión del mundo.

En segundo lugar, el debate sobre el significado selleva a cabo de manera conectada, pero de manera muy desigual en diferentes regiones del mundo. Por un lado, la experiencia de la pandemia es muy diferente en las clases medias de los estados de bienestar europeos, con respecto a países y barrios populares, donde la mayoría de los trabajadores dependen de la economía informal. Por otro lado, los movimientos populares y los intelectuales de cada región, han interpretado la crisis en función de la meta-narrativa que construyeron durante en los años anteriores. Por ejemplo, los movimientos populares latinoamericanos y sus intelectuales la enmarcaron en la "crisis de civilización", una narrativa mucho menos difundida en el Norte Global. Las redes internacionales de movimientos populares y activistas aspiran a superar estas divisiones promoviendo el intercambio de experiencias y análisis, abriendo espacios para un "diálogo global para el cambio sistémico ${ }^{21 "}$.

21 https://systemicalternatives.org/2020/04/29/global-dialogue-for-systemic-change 
En tercer lugar, la pandemia tiene lugar en un contexto geopolítico tenso (Bringel, 2020), que redefine las alianzas y las relaciones entre los gobiernos y sus ciudadanos. La democracia liberal está lejos de ser el único régimen y horizonte político compartido. Estos cambios también impactan a los movimientos sociales. Los activistas participan en esta batalla por el significado en circunstancias muy diferentes, y con riesgos muy distintos en regímenes autoritarios o democráticos (Bringel \& Pleyers, 2020).

\section{Conclusión}

Los debates sobre las interpretaciones de la crisis, presentados en la primera parte, pueden parecer actividades irrelevantes o meros juegos intelectuales. Sin embargo, es una etapa fundamental para poner las bases de políticas económicas y sociales que pueden remodelar la economía y la sociedad, al punto de impactar en la vida cotidiana de millones de personas.

La pandemia del COVID-19, ha devenido un campo de batalla para definir y proponer futuros alternativos. Los movimientos progresistas, capitalistas y reaccionarios, compiten para imponer sus narrativas y dar forma a las políticas y a la sociedad. Mientras, los gobiernos instan a volver a la "normalidad" pre-pandémica y buscan difundir su propia narrativa de la crisis. Este debate sobre interpretaciones de la crisis puede parecer un mero ejercicio intelectual, distante de la experiencia e intereses de la ciudadanía. Sin embargo, lo que está en juego, es la oportunidad de remodelar la economía y la sociedad, lo que sin duda tendrá un impacto considerable en la vida cotidiana de millones de personas y en la crisis ecologista.

¿Tendrán éxito hoy en día los movimientos populares y los activistas progresistas, donde fracasaron hace una década, tras la crisis financiera? La forma en que la humanidad saldrá de la pandemia del CoVID-19 dependerá de los avances de las ciencias y la investigación para encontrar una vacuna. También será el resultado de una lucha sobre los significados sociales, políticos y geopolíticos de la pandemia, así como sobre las visiones del mundo que deberían salir de ella. No hay un camino sencillo que conduzca de la pandemia a un mundo mejor, más ecológico y menos desigual.

Entender mejor la crisis y sus posibles consecuencias requiere analizar a profundidad la batalla que se libran actores sociales diversos por imponer un significado de la crisis y a partir de allí contribuir a forjar el mundo que emergerá de ella. Esta batalla no termina con el peak de la pandemia o con el confinamiento social. Estas son solo una de las etapas de una lucha prolongada para redefinir los modelos sociales, la economía mundial y los regímenes políticos del siglo XXI. 


\section{Referencias bibliográficas}

Afridi, L., \& Walters, C. (2020). Land Use Decisions Have Life and Death Consequences. Association for neighborhood and housing development, New York: ANHD. Recuperado de https://anhd.org/blog/land-use-decisionshave-life-and-death-consequences.

Amadeo, P. (Ed.) (2020). Sopa de Wuhan. La Plata: ASPO.

Boudon, R. (1989). L'idéologie. París: Seuil.

Bringel, B. (2020). Geopolítica de la pandemia, escalas de la crisis y escenarios en disputa. Geopolítica(s), 11, 173-187.

Bringel, B., \& Pleyers G. (Eds). (2020). Ecos globales de la pandemia. Política, movimientos y futuros alternativos. Buenos Aires: CLACSO. Manuscrito en preparación.

Escobar, A. (2018). Designs for the Pluriverse. Radical Interdependence, Autonomy, and the Making of Worlds. Durham, NC: Duke University Press.

Escobar, A. (2020). Post-pandemic transitions in a civilisational perspective. En Bringel B., Pleyers G. (Ed.), Ecos globales de la pandemia. Política, movimientos y futuros alternativos. Buenos Aires: CLACSO. Manuscrito en preparación.

Habermas, J. (1998). Facticidad y validez. Sobre el derecho y el Estado democrático de derecho en términos de teoría del discurso. Madrid: Trotta.

Jasper, J. (2012). Playing the Game. En J. Jasper \& J. Willem Duyvendak (Eds), Players and arenas: The interactive dynamic of protest. Amsterdam: Amsterdam University Press.

Klein, N. (2009). The Shock Doctrine. New York: Waterstone.

Kothari, A., Escobar, A., Salleh, A., Demaria, F., \& Acosta, A. (2020). Can the coronavirus save the planet? Recuperado de www.opendemocracy.net/en/ oureconomy/can-coronavirus-save-planet.

Pleyers, G. (2010). Alter-Globalization. Becoming Actors in the Global Age. Cambridge: Polity.

Pleyers, G. (2018). Movimientos sociales en el siglo XXI. Buenos Aires: CLACSO.

Pleyers, G. (2020). The pandemic is a battlefield. Artículo entregado para publicación.

Polanyi, K. (1944). The great transformation. Boston: Beacon Press. 
Polletta, F. (1998). Contending Stories: Narrative in Social Movements. Qualitative Sociology 21, 419-446.

Purkayastha, B. (2020). Divided We Stand. La pandemia en los Estados Unidos. En B. Bringel \& G. Pleyers (eds.), Ecos globales de la pandemia. Política, movimientos y futuros alternativos, Buenos Aires: CLACSO. Manuscrito en preparación.

Snow, D., \& Benford, R (2002). Master frames and cycles of protest. En A. Morris \& C. Mueller (Eds.), Frontiers in Social Movement Theory, pp. 133-155. New Haven, CT: Yale University Press.

Sousa Santos, B. (2019). The end of the cognitive empire. Durham, NC: Duke University Press.

Sousa Santos, B. (2020). La cruel pedagogía del virus. Buenos Aires: CLACSO.

Teivainen, T., \& Huotari, P. (2020). Horizontes democráticos en la gobernanza del coronavirus, En B. Bringel \& G. Pleyers (Eds.), Ecos globales de la pandemia. Política, movimientos y futuros alternativos. Buenos Aires: CLACSO. Manuscrito en preparación.

Touraine, A. (1973). Production de la société. París: Seuil.

Zarocostas, J. (2020). How to fight an infodemic (world report). The Lancet, 395(10225), 676.

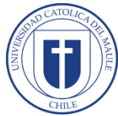

121

Dirección de correspondencia:

Geoffrey Pleyers

Profesor investigador del FNRS en la Universidad Católica de Lovaina, Bélgica.

Vicepresidente de la Asociación Internacional de Sociología (ISA) 2018-2022.

Presidente del Research Committee 47 "Social classes and social movements" en ISA, 2014-2018.

Promotor de la iniciativa Social Movements and the Global Age (SMAG).

Este texto ha contado con la revisión y edición de Juan Pablo Paredes, académico en

la Facultad de Ciencias Sociales y Económicas de la Universidad Católica del Maule.

Contacto: geoffrey.pleyers@uclouvain.be

Esta obra se encuentra bajo una Licencia de Creative Commons

Reconocimiento-NoComercial-Compartirlgual 4.0 Internacional 